\title{
Avaliação do tratamento integrativo no controle de parasitas gastrintestinais de ovinos
}

\author{
Evaluation of integrative treatment in the control of gastrointestinal parasites in sheep \\ Evaluación del tratamiento integrador en el control de parásitos gastrointestinales en ovinos
}

Recebido: 05/08/2021 | Revisado: 13/08/2021 | Aceito: 17/08/2021 | Publicado: 21/08/2021

\author{
Jairo Edelsio Gonçalves Pereira \\ ORCID: https://orcid.org/0000-0001-7832-1777 \\ Universidade José do Rosário Vellano, Brasil \\ E-mail: jairopereira@ veterinario.med.br \\ Michelli Pereira \\ ORCID: https://orcid.org/0000-0002-1203-8757 \\ Universidade José do Rosário Vellano, Brasil \\ E-mail: michellipr1981@gmail.com \\ Rebeca Gonçalves de Lima Magalhães \\ ORCID: https://orcid.org/0000-0001-6030-0441 \\ Instituto Federal do Sul de |Minas Gerais, Brasil \\ E-mail: rebecagoncalveslimamagalhaes@hotmail.com \\ Ricardo Passamani Melotti \\ ORCID: https://orcid.org/0000-0001-6652-9271 \\ Médicos Veterinários autônomos, Brasil \\ E-mail: Ricardo.gerentetecnico@ realh.com.br \\ Leandro Becalete Rizzomi \\ ORCID: https://orcid.org/0000-0001-8936-0616 \\ Médicos Veterinários autônomos, Brasil \\ E-mail: leandro-becalete@ hotmail.com \\ Elizângela Guedes \\ ORCID: https://orcid.org/0000-0003-4044-950X \\ Universidade José do Rosário Vellano, Brasil \\ E-mail: elizgguedes@gmail.com \\ José Antônio Dias Garcia \\ ORCID: https://orcid.org/0000-0002-4024-3045 \\ Universidade José do Rosário Vellano, Brasil \\ E-mail: jose.garcia@unifenas.br
}

\begin{abstract}
Resumo
Um dos principais entraves para o crescimento do rebanho ovino são as perdas ocasionadas pelas helmintoses gastrintestinais. Deste modo, o presente estudo teve como objetivo avaliar o efeito de dois tratamentos antiparasitários para ovinos infectados naturalmente, usando um tratamento alopático Cloridrato de Levamisol 5\% e um tratamento homeopático com o produto Homeocapriovi Verm 100, comparando as diferenças da contagem de ovos por grama de fezes (OPG) e oocistos por grama de fezes (OOPG) dos tratamentos e as concentrações séricas de proteínas totais, globulinas, albumina e a relação albumina/globulina dos tratamentos alopático e o homeopático na resposta imunológica frente às infecções parasitárias. Após análise dos resultados, tanto o produto alopático quanto o produto homeopático utilizado neste estudo preveniram o aumento de OPG para infecção por helmintos da ordem Strongylida e ambos os grupos não manifestaram sinais clínicos de coccidiose. Não houve diferença significativa entre os dois grupos na análise da média da concentração sérica das proteínas totais, albumina, globulina e a relação albumina/globulina. Embora o custo tenha sido mais elevado no tratamento homeopático, pode-se concluir que, o mesmo é uma alternativa eficiente no controle de parasitas do trato gastrintestinal de ovinos.
\end{abstract}

Palavras-chave: Homeopatia; OPG; Ovelha; Strongylida.

\begin{abstract}
One of the main obstacles to the growth of the sheep herd are the losses caused by gastrointestinal helminthiasis. Thus, the present study aimed to evaluate the effect of two antiparasitic treatments for naturally infected sheep, using an allopathic treatment with Levamisol Hydrochloride 5\% and a homeopathic treatment with the product Homeocapriovi Verm 100, comparing the differences in egg counts per gram of feces (OPG) and oocysts per gram of feces (OOPG) of treatments and serum concentrations of total proteins, globulins, albumin and the albumin/globulin ratio of allopathic and homeopathic treatments in the immune response to parasitic infections. After analyzing the results, both the allopathic product and the homeopathic product used in this study prevented the increase of OPG for
\end{abstract}


infection by Strongylide helminths and both groups did not show clinical signs of coccidiosis. There was no significant difference between the two groups in the analysis of the mean serum concentration of total proteins, albumin, globulin and the albumin/globulin ratio. Although the cost has been higher in homeopathic treatment, it can be concluded that it is an efficient alternative in the control of parasites in the gastrointestinal tract of sheep.

Keywords: Homeopathy; OPG; Sheep; Strongylide.

\section{Resumen}

Uno de los principales obstáculos para el crecimiento del rebaño ovino son las pérdidas provocadas por las helmintiasis gastrointestinales. Así, el presente estudio tuvo como objetivo evaluar el efecto de dos tratamientos antiparasitarios en ovejas naturalmente infectadas, utilizando un tratamiento alopático con Levamisol Clorhidrato al $5 \%$ y un tratamiento homeopático con el producto Homeocapriovi Verm 100, comparando las diferencias en el recuento de huevos por gramo de heces ( OPG) y ooquistes por gramo de heces (OOPG) de tratamientos y concentraciones séricas de proteínas totales, globulinas, albúmina y la relación albúmina / globulina de tratamientos alopáticos y homeopáticos en la respuesta inmune a infecciones parasitarias. Después de analizar los resultados, tanto el producto alopático como el homeopático utilizado en este estudio evitaron el aumento de OPG para la infección por helmintos Strongylide y ambos grupos no mostraron signos clínicos de coccidiosis. No hubo diferencias significativas entre los dos grupos en el análisis de la concentración sérica media de proteínas totales, albúmina, globulina y la relación albúmina / globulina. Aunque el costo ha sido mayor en el tratamiento homeopático, se puede concluir que es una alternativa eficaz en el control de parásitos en el tracto gastrointestinal de las ovejas.

Palabras clave: Homeopatía; OPG; Oveja; Strongylide.

\section{Introdução}

Uma das limitações para o crescimento dos rebanhos ovinos são as perdas geradas pelo parasitismo gastrintestinal. As altas taxas de mortalidade, o alto custo com medicamentos antiparasitários e principalmente o surgimento de cepas de parasitos resistentes aos anti-helmínticos, são fatores de prejuízos aos produtores de ovinos, sendo, os nematoides os que mais se destacam pertencentes a ordem Strongylida, e o gênero de maior prevalência é Haemonchus (Charlier et al., 2020; do Amarante \& Amarante, 2016).

Infecções por parasitas podem ocorrer de forma mistas e com diferentes graus de patogenicidade. Observa-se que animais com infecções parasitárias podem apresentar, anorexia, perda de peso, danos por ações espoliativas, toxicoirritativas e obstrutivas, cuja intensidade está diretamente relacionada ao nível de parasitismo, na qual, são dependentes de um conjunto de fatores extrínsecos e intrínsecos como: temperatura, precipitação pluviométrica, solo, tipo e manejo de pastagem, manejo dos animais, espécie, raça, idade, estado fisiológico e nutricional dos animais (Celi et al., 2017). Além disso, esses parasitas podem ocasionar lesões na mucosa intestinal, na qual observa-se as coccidioses, embora sejam mais frequentes em animais estabulados sua ocorrência não é incomum em animais criados em sistemas semi-intensivos (Macedo et al., 2019).

Neste sentido, é necessário a adoção de estratégias de controle dessas doenças de modo a garantir o bem-estar e sanidade dos animais, bem como para evitar perdas econômicas (Ahmed, 2017). O uso de drogas anti-helmínticas e anticoccidiostáticas é uma das principais estratégias adotadas em todo o mundo. Contudo, a restrição no uso dessas drogas e o desenvolvimento de resistência a esses medicamentos, são consequências da co-evolução parasita-hospedeiro, na qual, os parasitas sobrevivem à exposição de doses padrão recomendadas e são capazes de prosperar e se reproduzir abaixo de regimes de dosagem existentes. Assim, a frequência e dosagem do tratamento são geralmente os principais fatores que impulsionam o desenvolvimento de resistência aos anti-helmínticos (Zvinorova et al., 2016).

As avaliações de novas estratégias medicamentosas são importantes no sentido de avaliar seu potencial no tratamento de doenças parasitárias em ovinos. A utilização da homeopatia no controle parasitário de ovinos pode ser uma ferramenta importante no auxílio integrativo das parasitoses gastrintestinais, sendo um benefício em relação a produtos como antibióticos e agentes antiparasitários que deixam resíduos nos alimentos e prejudicam a saúde dos usuários finais. A homeopatia na produção animal tem a finalidade de prevenir o desenvolvimento de doenças, restabelecendo o equilíbrio imunológico ao invés de agir pontualmente sobre os micro-organismos (Zacharias et al., 2008). O presente estudo teve como objetivo avaliar o efeito 
de um tratamento homeopático e comparar com um tratamento alopático em ovinos infectados naturalmente.

\section{Metodologia}

O estudo foi realizado no setor de ovinocultura do IFSULDEMINAS - Campus Machado, entre março de 2017 a fevereiro de 2018. Foram utilizadas 60 ovelhas mestiças, provenientes do cruzamento de matrizes da raça Santa Inês e reprodutor da raça Dorper, criados em sistema semi-intensivo e infectados naturalmente. A alimentação dos animais durante o período experimental foi: pastagem Urochloa decumbens, não irrigada, alternada diariamente entre os grupos experimentais, silagem de milho fornecida de manhã e à tarde, misturada com concentrado formulado para ovinos com 14\% de Proteína Bruta na quantidade de $300 \mathrm{~g} / \mathrm{cab} / \mathrm{dia}$, sal mineral e água ad libitum.

Os animais passaram por exame clínico e pesagem. Na uniformização da carga parasitária foi utilizado o Cloridrato de Levamisol (CL 5\%), via oral (1 mL/10 kg) e o rebanho foi dividido aleatoriamente em dois grupos experimentais nas mesmas condições de carga parasitária, abaixo de 400 ovos por grama de fezes (OPG). O grupo controle alopático (TA, N=30), recebeu anti-helmíntico C.L. $5 \%$ via oral $(1 \mathrm{~mL} / 10 \mathrm{~kg})$, quando OPG ultrapassava 400, seguindo o tratamento tático já utilizado na unidade; o grupo homeopático $(\mathrm{TH}, \mathrm{N}=30$ ) foi tratado com o produto Homeocapriovi Verm 100 (Arsenicum álbum 10-24; Ferrum metallicum $10^{-30}$; Crotalus $10^{-60}$; Tanacetum vulgaris $10^{-24}$; Cuprum oxydatum $10^{-24}$; Sulphur $10^{-60}$; Artemisia marítima 10-30; China officinalis 10 ${ }^{-30}$; Spigelia anthelmintica 10-24; Apis melifica 10-30; Veículo (carbonato de cálcio) qsp $1000 \mathrm{~g}$ ), misturado no concentrado de forma homogênea na dosagem $10 \mathrm{~g}$ por animal/dia por via oral, fornecido em cocho coletivo. Quando os animais do grupo TH apresentaram OPG superior a 400, os mesmos recebiam C.L. 5\% via oral (1 mL/10 kg).

Foram coletadas 600 amostras de fezes, sendo 300 amostras para cada grupo, as quais foram encaminhadas para a Universidade Federal da Fronteira Sul (Laboratório de Doenças Parasitárias dos Animais Domésticos) para a realização dos exames parasitológicos de OPG e de OOPG, através da técnica de Gordon e Whitlock (1939).

A cada 3 meses, foram realizadas coletas de sangue, por venopunção da jugular externa com o uso de sistema a vácuo, e as amostras enviadas ao laboratório de Fisiologia e Reprodução Animal do IFSULDEMINAS - Campus Machado, onde foram centrifugadas, separado o soro, congelado. Os soros foram então enviados ao laboratório PETNOSTIC (Centro de Diagnóstico, Estudo e Pesquisas em Medicina Veterinária), para quantificar a concentração sérica de albumina, globulina e proteína total pelo método colorimétrico.

Os dados de temperatura e índice pluviométrico do período de março de 2017 a fevereiro de 2018 foram coletados diretamente da Empresa de Pesquisa Agropecuária de Minas Gerais- Fazenda Experimental de Machado - MG- Estação Climatológica Principal de Machado - INMET.

Utilizou-se um delineamento em parcela subdividida no tempo (Split Plot in Time), considerando os grupos tratado com Homeocapriovi Verm 100 e com Cloridrato de Levamisol 5\% como tratamento principal, e as datas de observações como tratamento secundário (Banzatto \& Kronka, 1989). Para a execução das análises, utilizou-se o programa Sisvar, pelo teste de Tukey a 5\% de probabilidade.

Para a análise estatística dos exames de sangue empregou-se o delineamento inteiramente casualizado e as análises foram realizadas dentro de cada coleta e as médias dos tratamentos também foram comparadas entre si e por tratamento, as diferenças entre médias foram realizadas pelo teste T Student a 5\% de significância.

\section{Resultados}

No presente estudo, quando associamos os valores médios de OPG (Figura 1) com o climograma (Figura 2) observouse uma prevalência de estrongilídeos no rebanho durante todo o experimento. A Figura 1 mostra os valores médios de OPG 
para estrongilídeos gastrintestinais nos tratamentos, frente às observações registradas no período experimental. Como o padrão utilizado no experimento foi vermifugar os animais acima de 400 OPG, 36,67 \% dos animais do grupo TA foram vermifugados com C.L. $5 \%$ via oral principalmente no período da seca e $23,34 \%$ do grupo TH durante o início do período chuvoso.

Figura 1: Valores médios de OPG para estrongilídeos gastrintestinais nos tratamentos com C.L. 5\% via oral (TA) e com produto Homeocapriovi Verm 100 na dosagem $10 \mathrm{~g}$ por animal/dia por via oral (TH).

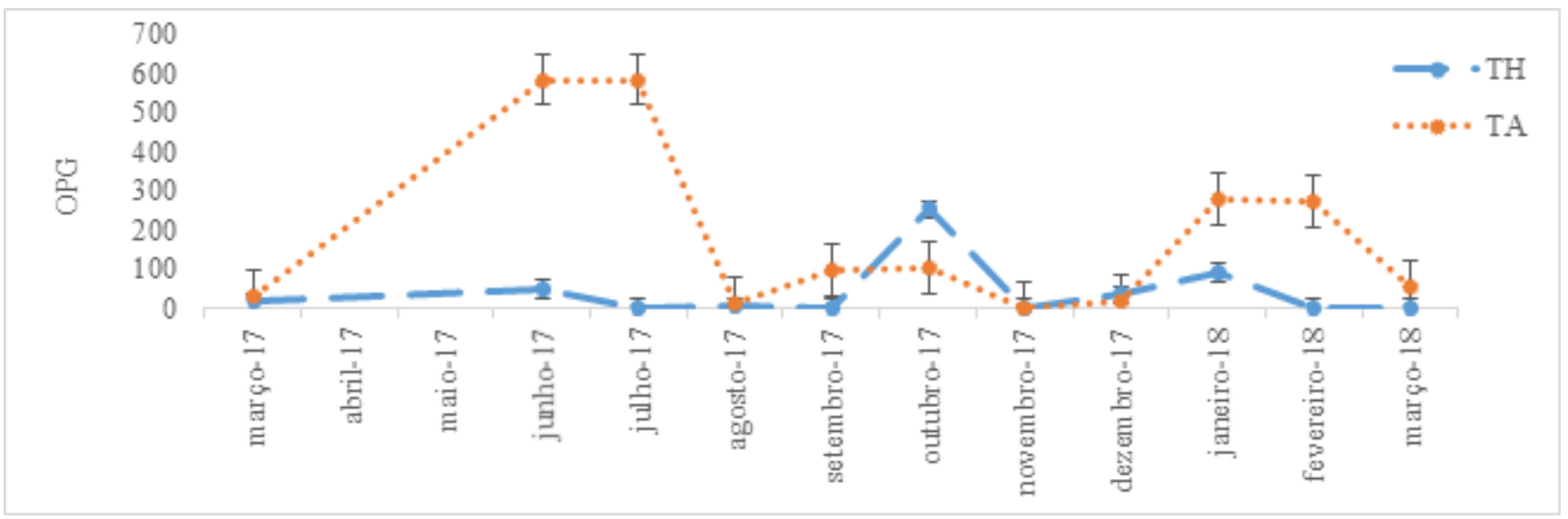

Fonte: Autores.

Figura 2: Climograma de Machado Março de 2017 a Fevereiro de 2018.

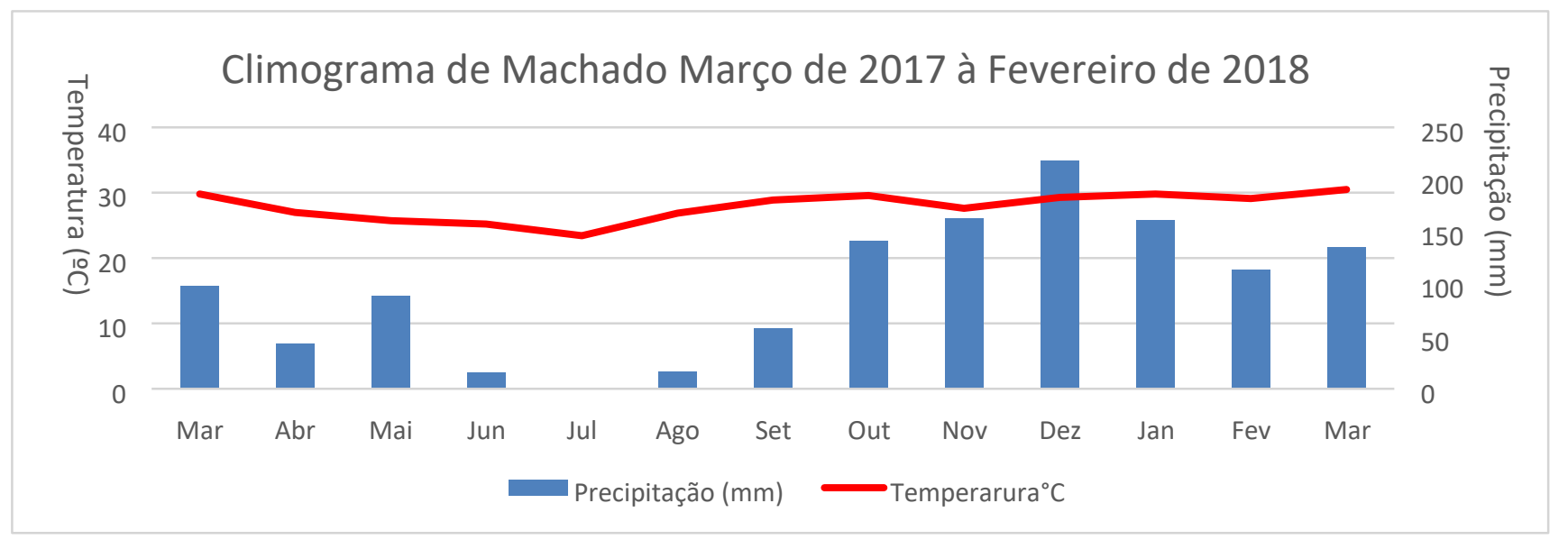

Fonte: Autores.

$\mathrm{Na}$ análise de variância da média de OPG houve diferença significativa $(\mathrm{P}>0,05)$ nos resultados dos exames para estrongilídeos gastrintestinais quando comparando as médias mensais dos dois tratamentos, no qual o grupo TH obteve melhor desempenho (Tabela 1), com menores médias mensais no OPG. As datas das observações foram consideradas tratamento secundário e não apresentaram diferenças significativas $(\mathrm{P}>0,05)$. 
Tabela 1: Valores médios de OPG para estrongilídeos gastrintestinais nos tratamentos com C.L. 5\% via oral (TA) e com produto Homeocapriovi Verm 100 na dosagem $10 \mathrm{~g}$ por animal/dia por via oral (TH).

\section{TRATAMENTO}

Resultados expressos em média \pm desvio padrão. Letras e números diferentes diferem significativamente [letra a, corresponde às datas de observações e os números as médias mensais do OPG (Split plot in Time)]. Fonte: Autores.

Para os resultados de OOPG, ambos os grupos não apresentaram diferença $(\mathrm{P}>0,05)$ na maior parte do período experimental (Figura 3). No início do período das águas, observou-se maior número de animais com presença de coccídeos nas fezes com predominância do OOPG no grupo TA (no primeiro pico manifestado na figura 3), contudo, sem manifestação clínica de coccidiose no rebanho estudado, o que já era esperado, pois o sistema de criação era semi-intensivo e o tratamento testado não incorpora o tratamento de protozoários.

Figura 3: Valores médios de OOPG para coccídeos gastrintestinais nos tratamentos com C.L. 5\% via oral (TA) e com produto Homeocapriovi Verm 100 na dosagem $10 \mathrm{~g}$ por animal/dia por via oral (TH).

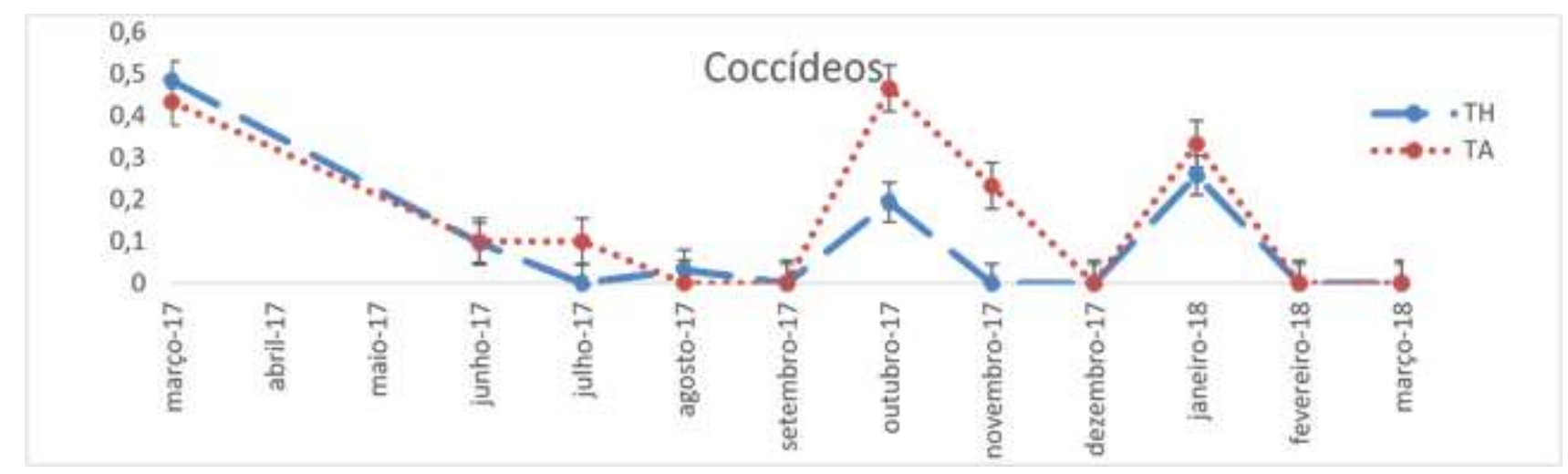

Fonte: Autores.

Para a concentração sérica das proteínas totais, albumina, globulina e a relação albumina/globulina das 4 coletas realizadas, não houve diferença significativa (P>0,05) entre os dois grupos (Tabela 2). Da mesma forma, ao avaliar os dados de cada coleta e comparar o resultado dos dois grupos, eles não apresentaram diferença (dados não relatados). 
Tabela 2: Comparação da média da concentração sérica das proteínas totais, albumina, globulina e a relação albumina/globulina das 4 coletas realizadas no experimento.

\begin{tabular}{cllll}
\hline Tratamento & $\begin{array}{l}\text { Proteínas Totais } \\
(\mathbf{m g} / \mathbf{d L})\end{array}$ & $\begin{array}{l}\text { Albumina } \\
(\mathbf{m g} / \mathbf{d L})\end{array}$ & $\begin{array}{l}\text { Globulina } \\
(\mathbf{m g} / \mathbf{d L})\end{array}$ & $\begin{array}{l}\text { Relação } \\
\text { Albumina/Globulina }\end{array}$ \\
\hline TH & $4,9 \pm 0,9$ & $2,5 \pm 0,4$ & $2,4 \pm 0,8$ & $1,1 \pm 0,3$ \\
\hline TA & $4,8 \pm 1,0$ & $2,6 \pm 0,6$ & $2,2 \pm 0,6$ & $1,2 \pm 0,3$ \\
\hline
\end{tabular}

Resultados expressos em média \pm desvio padrão. (Teste T Student $\mathrm{P}<0,05$ ). Fonte: Autores.

Na análise comparativa das médias da concentração sérica das proteínas totais, albumina, globulina e a relação albumina/globulina das 4 coletas realizadas nos animais tratados com C.L. 5\% (grupo TA), observou na coleta do mês de agosto uma diminuição das concentrações séricas de proteínas totais, albuminas e a relação albumina/globulina. Contudo, não foram observadas diferenças significativas $(\mathrm{P}<0,05)$ da concentração de globulina nas diferentes coletas (Tabela 3$)$.

Tabela 3: Comparação da média da concentração sérica das proteínas totais, albumina, globulina e a relação albumina/globulina das 4 coletas realizadas no grupo TA.

\begin{tabular}{|c|c|c|c|c|c|}
\hline Coletas & $\begin{array}{l}\text { Proteínas } \\
(\mathrm{mg} / \mathrm{dL})\end{array}$ & Totais & $\begin{array}{l}\text { Albumina } \\
\text { (mg/dL) }\end{array}$ & $\begin{array}{l}\text { Globulina } \\
\text { (mg/dL) }\end{array}$ & $\begin{array}{l}\text { Relação } \\
\text { Albumina/Globulina }\end{array}$ \\
\hline Maio & $4,8 \pm 0,5^{\mathrm{ab}}$ & & $2,6 \pm 0,3^{\mathrm{ab}}$ & $2,2 \pm 0,4^{\mathrm{a}}$ & $1,2 \pm 0,2^{\mathrm{ab}}$ \\
\hline Agosto & $4,0 \pm 0,8^{c}$ & & $2,2 \pm 0,6^{b}$ & $2,0 \pm 0,3^{a}$ & $1,0 \pm 0,2^{\mathrm{b}}$ \\
\hline Novembro & $5,3 \pm 0,4^{\mathrm{a}}$ & & $2,9 \pm 0,5^{\mathrm{a}}$ & $2,4 \pm 0,3^{a}$ & $1,2 \pm 0,2^{a b}$ \\
\hline Fevereiro & $4,5 \pm 0,7^{b}$ & & $2,5 \pm 0,4^{a b}$ & $2,0 \pm 0,4^{\mathrm{a}}$ & $1,3 \pm 0,2^{\mathrm{a}}$ \\
\hline
\end{tabular}

Resultados expressos em média \pm desvio padrão. Letras diferentes nas colunas diferem significativamente (Teste de Tukey 0,05$)$. Fonte: Autores.

A análise comparativa das médias da concentração sérica das proteínas totais, albumina, globulina e a relação albumina/globulina das 4 coletas realizadas nos animais tratados com o produto homeopático (grupo TH), observou na coleta do mês de agosto uma diminuição das concentrações séricas de proteínas totais, albuminas e globulina. Contudo, não foram observadas diferenças significativas $(\mathrm{P}<0,05)$ na relação albumina/globulina nas diferentes coletas $($ Tabela 4$)$.

Tabela 4: Comparação da média da concentração sérica das proteínas totais, albumina, globulina e a relação albumina/globulina das 4 coletas realizadas no grupo TH.

\begin{tabular}{lllll}
\hline Coletas & $\begin{array}{l}\text { Proteínas } \\
\text { Totais }(\mathbf{m g} / \mathbf{d L})\end{array}$ & $\begin{array}{l}\text { Albumina } \\
(\mathbf{m g} / \mathbf{d L})\end{array}$ & $\begin{array}{l}\text { Globulina } \\
(\mathbf{m g} / \mathbf{d L})\end{array}$ & $\begin{array}{l}\text { Relação } \\
\text { Albumina/Globulina }\end{array}$ \\
\hline Maio & $4,9 \pm 0,5^{\mathrm{a}}$ & $2,5 \pm 0,3^{\mathrm{ab}}$ & $2,4 \pm 0,4^{\mathrm{a}}$ & $1,1 \pm 0,2^{\mathrm{a}}$ \\
\hline Agosto & $4,2 \pm 0,7^{\mathrm{b}}$ & $2,3 \pm 0,5^{\mathrm{b}}$ & $1,8 \pm 0,4^{\mathrm{b}}$ & $1,2 \pm 0,3^{\mathrm{a}}$ \\
\hline Novembro & $5,0 \pm 0,5^{\mathrm{a}}$ & $2,7 \pm 0,3^{\mathrm{a}}$ & $2,4 \pm 0,3^{\mathrm{a}}$ & $1,2 \pm 0,2^{\mathrm{a}}$ \\
\hline Fevereiro & $4,9 \pm 0,3^{\mathrm{a}}$ & $2,6 \pm 0,3^{\mathrm{ab}}$ & $2,2 \pm 0,3^{\mathrm{ab}}$ & $1,2 \pm 0,2^{\mathrm{a}}$ \\
\hline
\end{tabular}

Resultados expressos em média \pm desvio padrão. Letras diferentes nas colunas as diferem significativamente (Teste de Tukey 0,05$)$. Fonte: Autores. 


\section{Discussão}

O grupo TH apresentou uma menor prevalência de estrongílideos, quando comparado ao grupo TA principalmente no período da estação seca, na região sul de Minas Gerais. Quando comparado às médias mensais os tratamentos não se diferiram estatisticamente $(\mathrm{P}>0,05)$, isso revelou uma eficácia do tratamento homeopático em diminuir a infecção verminótica no grupo TH. O C.L. 5\% apresentou menor prevalência parasitária no período das águas, semelhante aos animais tratados com homeopatia nesse período. Além disso, os animais do grupo TH, que receberam C.L., podem ter sido beneficiados por um sinergismo de adição entre o C.L. e o produto homeopático, conferindo defesa efetiva contra a verminose, mantendo parâmetros de OPG baixos também durante o período das águas. Embora no sistema de criação do rebanho estudado as pastagens não fossem irrigadas, no período da estação seca, chuvas leves foram suficientes para garantir umidade adequada para os estádios de vida livre dos parasitas. Além disso, as condições de temperatura e umidade registradas neste período, foram favoráveis ao desenvolvimento larval, permitindo assim, um aumento no tempo de sobrevivência das larvas infectantes no ambiente, e desfavorecendo a dessecação e destruição de ovos e larvas na pastagem.

O C.L. é um anti-helmíntico com eficácia entre 90 a 100\% para ovinos (Melo et al., 2002; Duarte et al., 2012) e além disso, é um imunomodulador da resposta celular e humoral (Cuesta et al., 2002). Para que haja este tipo de resposta há a necessidade de que seja instituído tratamento a longo prazo (Souza, 2010). Podemos observar isso no nosso estudo, onde os animais do grupo TA receberam C.L. 5\% em 8 doses distribuídas nos meses de abril a setembro, e nos meses de janeiro e fevereiro, seguindo o tratamento tático. A menor prevalência de estrongílideos nos animais tratados com homeopatia pode ser por aumentar a produção e longevidade de anticorpos produzidos, provocando alterações fisiológicas capazes de melhorar o desempenho animal (Varshney \& Naresh, 2005; Chabel et al., 2009). Além disso, o rebanho estudado já utilizava o C.L. 5\% na maioria das vermifugações e com isso, os nematoides podem ter desenvolvido resistência à droga (Vieira, 2008).

No estudo de Neves et al. (2012) analisando cabras tratadas com Arsenicum álbum e Sulphur, administrado via oral por 62 dias, obtiveram com o medicamento homeopático Sulphur menores médias no OPG, observando ainda maior eficácia deste em relação ao Arsenicum álbum, pois manteve a população de estrongílideos baixa e sob controle, porém ambos foram capazes de manter as populações baixas. Médias menores foram encontradas nos ovinos do grupo TH do presente estudo, quando comparadas com os estudos de Neves et al. (2012). Isso também pode ser somado a outros princípios presentes no produto homeopático utilizado neste estudo, como a Spigelia anthelmintica, que apresentou bons resultados inibindo a eclosão de larvas de nematoides (Camurça-Vasconcelos et al., 2005); a China officinalis que atuam de forma significativa nos distúrbios por perda de líquidos orgânicos tais como as hemorragias e as diarreias, nos transtornos no aparelho digestivo como cólicas e má digestão, na hipertrofia do fígado e do baço com sensibilidade ao toque e nas hemorragias intestinais (Boericke, 2005; Lathoud, 2010; Ancken; Torro 2016).

De acordo com Amarante (2007), protozoários como coccídeos têm a sua transmissão facilitada em confinamento. Apesar do manejo neste estudo ser semi-intensivo, a frequência de aparecimento nas contagens de OOPG para coccídeos foi sempre baixa, os tratamentos com anti-helmínticos não abrangem os coccídeos, porém no período das águas foi observado uma melhor resposta de defesa dos animais. Para Macedo et al. (2019), animais saudáveis, mantidos em condições de manejo satisfatórias, a ingestão contínua de oocistos, em pequena quantidade, induz o desenvolvimento de resposta imunológica protetora, a qual é suficiente para limitar, mas não para extinguir a infecção.

Ambos os tratamentos utilizados no presente experimento apresentaram resultados satisfatórios no controle de verminoses na ovinocultura semi-intensiva do sul de Minas Gerais. Contudo, o custo mensal do produto homeopático utilizado neste experimento foi de US\$ 8,34 por animal se comparado com o produto alopático que foi de US\$ 4,81 (valor com base na média mensal do dólar no período de 2017-2018). A aplicação do produto homeopático não afetou a rotina de manejo para os 
animais, além disso, não apresenta resíduos na carne e no leite, logo representando baixo impacto ambiental, pois a homeopatia utiliza substâncias diluídas e dinamizadas e vem se mostrando como uma ferramenta tecnológica com grande potencial para atender às exigências do mercado consumidor atual (Giuliotti et al., 2016).

\section{Conclusão}

O tratamento homeopático preveniu as infecções parasitárias, com respostas imunológicas semelhantes ao tratamento alopático, contudo o tratamento homeopático não afetou a rotina de manejo, sendo uma importante alternativa de controle antihelmíntico nos rebanhos ovinos. Com a crescente demanda e preocupação com o desenvolvimento sustentável e a busca por tecnologias que sejam de baixo custo e menos nocivas à saúde humana e ao meio ambiente, a homeopatia tem se mostrado bastante promissora dentro do controle integrado das parasitoses, tornando-se necessário investir em pesquisas que visem a busca de resultados observados a longo prazo para maior compreensão dos mecanismos de ação em que atuam.

\section{Referências}

Ahmed, J. (2017). Gastrointestinal nematode parasites of small ruminants and anthelmintics efficacy test in sheep of haramaya district, Eastern Ethiopia. Animal and Veterinary Sciences, 5(3), 39. https://doi.org/10.11648/j.avs.201705

Amarante, A. F. T., \& Sales, R. O. (2007). Control of endoparasitoses of sheeps: a revision. Revista Brasileira de Higiene e Sanidade Animal, 1(2), 14-36. https://doi.org/10.5935/1981-2965.20070007

do Amarante, A. F. T., \& Amarante, M. R. V. (2016). Avanços no diagnóstico das infecções por nematódeos gastrintestinais em ruminantes. Brazilian Journal of Veterinary Research and Animal Science, 53(2), 127-137. https://doi.org/10.11606/issn.1678-4456.v53i2p127-137

Ancken a. C. B. V.; Torro A. R. (2016). Homeopatia no tratamento de doenças hepáticas e vesiculares em cães e gatos. Revista Conselho Federal de Medicina Veterinária, (7), $42-46$.

Banzatto, D.A, \& Kkronka, S.N. (1989). Experimentação agrícola Jaboticabal: FUNEP.

Boericke W. (2005). Manual de Bolsillo de Materia Medica Homeopatica. (9a ed.), New Dehi.

Camurça-Vasconcelos, A. L. F., Morais, S. M., Santos, L. F. L., Rocha, M. F. G., \& Bevilaqua, C. M. L. (2005). Validação de plantas medicinais com atividade anti-helmíntica. Revista Brasileira de Plantas Medicinais, 7(3), 97-106.

Celi, P., Cowieson, A. J., Fru-Nji, F., Steinert, R. E., Kluenter, A. M., \& Verlhac, V. (2017). Gastrointestinal functionality in animal nutrition and health: New opportunities for sustainable animal production. Animal Feed Science and Technology, 234, 88-100. https://doi.org/10.1016/j.anifeedsci.2017.09.012

Chabel, J. C., Onselen, V. J. van, Morais, M. D. G., Cortada Neto, I. M., \& Tedeschi, B. P. (2009). Efeito de um complexo homeopático"Homeobase Convert $\mathrm{H}{ }^{\circledR}$ " em ovinos sob condições de restrição alimentar. Brazilian Journal of Veterinary Research and Animal Science, 46(5), 412. https://doi.org/10.11606/issn.1678-4456.bjvras.2009.26792

Charlier, J., Höglund, J., Morgan, E. R., Geldhof, P., Vercruysse, J., \& Claerebout, E. (2020). Biology and Epidemiology of Gastrointestinal Nematodes in Cattle. Veterinary Clinics of North America - Food Animal Practice, 36(1), 1-15. https://doi.org/10.1016/j.cvfa.2019.11.001

Cuesta, A., Esteban, M. A., \& Meseguer, J. (2002). Levamisole is a potent enhancer of gilthead seabream natural cytotoxic activity. Veterinary Immunology and Immunopathology, 89(3-4), 169-174. https://doi.org/10.1016/S0165-2427(02)00220-9

Duarte, E. R., Silva, R. B., Vasconcelos, V. O., Nogueira, F. A., \& Oliveira, N. J. F. (2012). Diagnóstico do controle e perfil de sensibilidade de nematódeos de ovinos ao albendazol e ao levamisol no norte de Minas Gerais. Pesquisa Veterinaria Brasileira, 32(2), 147-152. https://doi.org/10.1590/S0100736X2012000200010

Giuliotti, L., Pisseri, F., di Sarsina, P. R., Azzarello, B. M., Terracciano, G., \& Benvenuti, M. N. (2016). Gastrointestinal strongyles burden monitoring in a flock of Zerasca sheep treated with homeopathy. European Journal of Integrative Medicine, 8(3), 235-238. https://doi.org/10.1016/j.eujim.2015.09.133

Gordon, H.M.; Whitlock, H. V. (1939). A new technique for counting nematode eggs in sheep faeces. Journal of Council of Science and Industry Research. Journal of Council of Science and Industry Research., 12 (1): 50-52.

Lathoud J. A. (2010). Estudos de Matéria Médica Homeopática. (3a ed.), Organon.

Macedo, L. O. de, Santos, M. A. B., Silva, N. M. M. da, Barros, G. M. M. do R., Alves, L. C., Giannelli, A., ... Carvalho, G. A. de. (2019). Morphological and epidemiological data on Eimeria species infecting small ruminants in Brazil. Small Ruminant Research, 171, 37-41. https://doi.org/10.1016/j.smallrumres.2018.12.006

Melo, A. C. F. L., \& Bevilaqua, C. M. L. (2002). Resistência anti-helmíntica em nematóides de pequenos ruminantes: uma revisão. Revista Ciência Animal, 12(1). 
Research, Society and Development, v. 10, n. 10, e594101019124, 2021

(CC BY 4.0) | ISSN 2525-3409 | DOI: http://dx.doi.org/10.33448/rsd-v10i10.19124

Neves, H. H., Hötzel, M. J., Honorato, L. A., da Fonseca, C. E. M., da Mata, M. G. F., \& da Silva, J. B. (2012). Controle de verminoses gastrintestinais em caprinos preparados homeopáticos. Revista Brasileira de Agroecologia, 7 (1). http://revistas.aba-agroecologia.org.br/index.php/rbagroe cologia/article/view/10036/0

Souza D.R.D. (2010). Efeito do levamisol sobre leucócitos periféricos de cães com erliquiose. 2010, 58p. Dissertação (Sanidade Animal) Faculdade de Agronomia e Medicina Veterinária da Universidade Federal de Mato Grosso, MT

Varshney, J. P., \& Naresh, R. (2005). Comparative efficacy of homeopathic and allopathic systems of medicine in the management of clinical mastitis of Indian dairy cows. Homeopathy, 94(2), 81-85. https://doi.org/10.1016/j.homp.2004.11.013

Vieira, L. S. (2008). Métodos alternativos de controle de nematóides gastrintestinais em caprinos e ovinos. Tecnol. \& Ciên. Agropec, 2 (2): $49-56$.

Zacharias, F., Guimarães, J. E., Araújo, R. R., Almeida, M. A. O., Ayres, M. C. C., Bavia, M. E., \& Mendonça-Lima, F. W. (2008). Effect of homeopathic medicines on helminth parasitism and resistance of Haemonchus contortus infected sheep. Homeopathy, 97 (3), 145-151. https://doi.org/10.1016/j.homp.2008.05.004

Zvinorova, P. I., Halimani, T. E., Muchadeyi, F. C., Matika, O., Riggio, V., \& Dzama, K. (2016). Breeding for resistance to gastrointestinal nematodes - the potential in low-input/output small ruminant production systems. Veterinary Parasitology, 225, 19-28. https://doi.org/10.1016/j.vetpar.2016.05.015 